\title{
AS OUVIDORIAS LEGISLATIVAS E O SEU PAPEL NA RECONSTRUÇÃO DAS ATIVIDADES TÍPICAS DO PODER LEGISLATIVO
}

Douglas Moreno'

\begin{abstract}
Resumo
Este trabalho visa explorar o papel das Ouvidorias Legislativas no Brasil e destacar o seu papel na reconstrução das atividades típicas do Poder Legislativo. De início, é exposta a situação atual das Ouvidorias Legislativas em comparação com as demais Ouvidorias Públicas, tomando-se como exemplo o modelo atual de algumas Ouvidorias de Assembleias Legislativas no Brasil. Em seguida, toma-se como referência o modelo de países como a Nova Zelândia e a Austrália denominado Ombudsmen, que são Ouvidorias Legislativas consagradas como exemplos de boa governança, ilustrando-se alguns aspectos comparativos com as nossas Ouvidorias. Ao final, o trabalho sugere estratégias de como a atuação das Ouvidorias Legislativas pode provocar mudanças de paradigmas na atividade legislativa e no resgate da função fiscalizatória do Poder Legislativo.
\end{abstract}

Palavras-chave: Ouvidorias Legislativas. Ouvidorias Parlamentares. Ouvidorias Públicas. Fiscalização. Controle Externo. Administração Pública. Poder Legislativo. Assembleia Legislativa. Tribunal de Contas.

1 Procurador Legislativo e Ouvidor Executivo da Assembleia Legislativa do Estado de Pernambuco. Mestre (LLM) em Administrative Law pela Victoria University of Wellington na Nova Zelândia. Bolsista do programa australiano Professional Development Scholarship Endevour Award, com atuação no Ombudsman SA, Adelaide, Sul da Austrália. (dmoreno@alepe.pe.gov.br)

Rua do Sossego, 591 - Boa Vista - Recife,PE - CEP 50100-150 Fone: 81989445650 


\section{Abstract}

This paper aims to explore the role of Parliamentarian Ombudsmen in Brazil and to highlight their role in the reconstruction of the typical activities of the Legislative Branch. Initially, the situation of the Parliamentarian Ombudsmen is exposed, such as the current model of Ombudsman's Offices of Legislative Assemblies in Brazil, and compared with the other Public Ombudsman's Offices. Further, the studies involve the New Zealand and Australia Parliamentarian Ombudsmen which are considered models of good governance practices as a reference, including some comparative perspectives with Parliamentarian Ombudsmen in Brazil. Finally, the paper suggests strategies that can lead to paradigm shifts into legislative activity and contribution to restore the oversight function.

Keywords: Parliamentary Ombudsmen. Ombudsman's Office. Public Ombudsman's Offices. Public Administration. Supervision. External Control. Legislative Power. Court of Accounts. 


\section{INTRODUÇÃO}

No Brasil, as Ouvidorias Legislativas ou Parlamentares são as Ouvidorias Públicas vinculadas ao Poder Legislativo da União, dos Estados e dos Municípios. As Ouvidorias Legislativas do Poder Legislativo da União incluem as do Senado Federal, da Câmara dos Deputados e do Tribunal de Contas da União. Por sua vez, as Ouvidorias Legislativas do Estado são aquelas que funcionam nas Assembleias Legislativas Estaduais e nos Tribunais de Contas dos Estados e Municípios, enquanto as Ouvidorias situadas nas Câmaras Municipais são aquelas integrantes do Poder Legislativo do Município.

De modo geral, todavia, pouco tem sido o enfoque dado às Ouvidorias Legislativas no nosso país.

Enquanto as Ouvidorias do Poder Executivo, por exemplo, já atingem um nível razoável de estrutura, organização, integração e destaque no setor público, as Ouvidorias Legislativas são núcleos incipientes que não alcançaram ainda a posição de reconhecimento que poderiam usufruir.

Como se não bastasse, em diversas localidades do país, elas funcionam precariamente ou sequer existem, a exemplo de algumas Ouvidorias de Assembleias Legislativas Estaduais e Ouvidorias de Câmaras Municipais. Esta situação cria um paradoxo indesejável que é a situação de desigualdade entre os cidadãos brasileiros que podem ser "mais bem ouvidos" ou até "deixam de ser ouvidos", a depender de onde residem.

Mais grave ainda, há determinadas demandas que reclamam a atuação exclusiva do Poder Legislativo e não de outros Poderes, a exemplo da inovação legislativa e do controle externo. Logo, se as Ouvidorias Legislativas não estão devidamente posicionadas na atividade público-administrativa, o cidadão poderá não ter o canal apropriado para que suas manifestações sejam respondidas, sobremodo quando o tema envolver esta atuação que é típica e exclusiva do Poder Legislativo.

Neste artigo, objetiva-se resgatar a importância das Ouvidorias Legislativas utilizando-se como argumento o prestígio de que gozam outras Ouvidorias Parlamentares de outros países, como as da Nova Zelândia e da Austrália. Antes, porém, há necessidade de ilustrar a situação atual de algumas Ouvidorias Legislativas a exemplo das existentes nas Assembleias Legislativas Estaduais no Brasil, para que haja a percepção de como o modelo está sendo tratado e quais mudanças de parâmetros são necessárias para que haja uma melhoria do exercício das funções do Poder Legislativo.

\section{Situação das Ouvidorias Legislativas: o Caso das Ouvidorias Legislativas de Assembleias Legislativas}

Alguns modelos vigentes foram pesquisados através dos seus portais de transparência e da página oficial disponibilizada na internet, utilizando-se as siglas de cada Estado para identificar de qual Casa Legislativa ela é integrante, justamente com o objetivo de evidenciar como está sendo implementado o sistema de Ouvidorias nas Assembleias Legislativas do país. 
No que diz respeito à sua instituição formal, temos exemplos de Ouvidorias que são criadas através de Resolução interna (MG - SP - RS - AL) $)^{2}$, de Regimento Interno $(M A)^{3}$, de Decreto-Legislativo $(P R)^{4}$ e de Leis Ordinárias $(P E-P B)^{5}$, variando o seu posicionamento no organograma da instituição, sendo algumas vinculadas à Mesa Diretora $(R S-M T)^{6}$, enquanto que outras aparecem subordinadas á Presidência do órgão $(S P-P E)^{7}$, e algumas não fazem parte sequer formalmente desta estrutura $(\mathrm{GO})^{8}$.

As Ouvidorias Legislativas têm sido ocupadas pelos próprios parlamentares ou ex-parlamentares, cuja designação como Ouvidor-Geral pode ocorrer através de eleição, durante a escolha da Mesa Diretora $(\mathrm{PE})^{9}$, ou já definida internamente pela composição da própria Mesa Diretora quando esta é escolhida previamente $(\mathrm{MA})^{10}$, possuindo o Ouvidor normalmente o mesmo mandato que é conferido à Mesa Diretora de 2 (dois) anos (MG - PE) ${ }^{11}$, podendo ser reconduzido para os próximos 2 (dois) anos.

O perfil daqueles que assumem a função de Ouvidor-Geral de Assembleias Legislativas normalmente é a de um ex-deputado ou deputado da base governista e/ou que pode integrar a Comissão de Ética da Casa Legislativa, sendo hipótese remota, devido a questões estratégicas e políticas, que o Ouvidor-Geral seja um membro da oposição ao governo vigente. A situação mais peculiar é a da Assembleia Legislativa do Estado da Paraíba, cujo Ouvidor é um cidadão escolhido por um Conselho Consultivo composto por dez instituições da sociedade civil ${ }^{12}$.

Em alguns casos há um Ouvidor Substituto(SP) ${ }^{13}$ ou Ouvidor Executivo $(\mathrm{PE})^{14}$, com delegação de atribuições recebidas pelo Ouvidor-Geral, os quais conduzem as questões técnicas e administrativas do departamento, resolvendo sempre as questões mais comuns e reportando ao Ouvidor-Geral as situações mais complexas.

Há Ouvidorias Legislativas que lidam com a gestão da informação e com a elaboração/revisão do Portal da Transparência, com papel fundamental no cumprimento da lei de acesso à informação

\section{2 www.alemg.gov.br} www.alesp.gov.br www.alrs.gov.br

3 www.alma.gov.br

4 http://www.alep.pr.gov.br/sala_de_imprensa/noticias/projeto-que-cria-ouvidoria-da-assembleia-e-aprovado-emsegunda-votacao-1

5 www.alepe.pe.gov.br

6 www.alrs.gov.br

7 www.alesp.gov.br www.alepe.pe.gov.br

8 https://portal.al.go.leg.br/arquivos/transparencia/organograma_07_2016.pdf

9 www.alepe.pe.gov.br

10 www.alma.gov.br

11 www.almg.gov.br www.alepe.pe.gov.br

12 www.al.pb.leg.br/ouvidoria-da-alpb

13 www.al.sp.gov.br/participe/ouvidoria/

$14 \mathrm{http}: / /$ legis.alepe.pe.gov.br/arquivoTexto.aspx?tiponorma=1\&numero=15700\&complemento=0\&ano=2015\&tipo= 
do órgão a que se vinculam (PE - DF $)^{15}$, como aquelas que se confundem como um serviço de informação ao cidadão (SIC / Fale Conosco), de atendimento através de telefone e/ou por outros meios eletrônicos (PA - PI - MS - BA - RJ) ${ }^{16}$.

Existem Ouvidorias Legislativas que chegam até a realizar ações sociais (AM) ${ }^{17}$ e são divulgadas externamente em carta de serviço ao cidadão $(\mathrm{MT})^{18}$, enquanto outras atuam exclusivamente de forma interina ( $G O$ - ES) ${ }^{19}$ ou mesmo virtual $(R J-P I)^{20}$, como órgão que protocola as manifestações que são recebidas ou as recebe através do e-mail eletrônico do órgão, sem muita visibilidade externa.

De modo geral, as Ouvidorias de Assembleias Legislativas enfrentam resistência no próprio órgão a que pertencem para atuar de forma mais autônoma e independente, pois muitas vezes não são reconhecidas pelos demais setores da própria instituição, com o agravante de não terem um espaço físico apropriado para as suas atividades, ou ainda de suas funções serem minimizadas como se fossem um apêndice do órgão ou confundidas com o trabalho das assessorias de deputados, do setor de comunicação, das corregedorias, das controladorias e das consultorias das Casas Legislativas.

A "colcha de retalhos" que caracteriza as Ouvidorias das Assembleias Legislativas no nosso país revela a falta de uniformidade de critérios e condições para que essas unidades tenham maior vigor e consistência nas suas ações, sendo evidente a carência de um modelo sólido, fato que repercute negativamente no sentido de que sejam mais reconhecidas.

\section{Ombudsmen na Austrália e na Nova Zelândia, e as Ouvidorias Públicas Brasileiras: algumas semelhanças e diferenças}

Trata-se de um engano comum descartar qualquer análise comparativa entre as Ouvidorias Públicas brasileiras e aquelas existentes em outros países, alegando que temos sistemas administrativos diferentes e realidades bem distintas.

É importante frisar que em muitos países, assim como no Brasil, há igualmente a clássica tripartição de poderes, com a aplicação da teoria dos balanços e contrapesos, com mecanismos de controle recíprocos e garantia de acesso à informação pública como direito fundamental, existindo

www.alepe.pe.gov.br www.cl.df.gov.br

www.alpa.gov.br

www.transparencia.al.ms.gov.br/pages/index.php/faleconosco

www.alba.gov.br

www.alerj.gov.br

17 www.alam.gov.br

18 www.al.mt.gov.br/arquivos/institucional/carta-de-servicos-ao-cidadao-2016.pdf

19 www.algo.gov.br www.ales.gov.br

20 www.alpi.gov.br 
órgãos nesses países que também atuam como elo entre o cidadão e o governo, o que implica dizer que há similaridades na concepção dessas instituições, embora pertençam a regimes de governo diferentes, sendo as distinções mais reservadas ao rol de atribuições e ao grau de prestígio que recebem.

Por exemplo, na Nova Zelândia e na Austrália, países que figuram frequentemente em posições invejáveis no índice que mede o nível de percepção de corrupção e transparência governamental ${ }^{21}$, o que se denomina "Ombudsmen" ou "Parliamentary Ombudsmen" são os núcleos estatais já consagrados e amadurecidos como canal de interação do cidadão com o governo, elevados à categoria de exemplos essenciais de boa prática governamental ("good governance practice").

A Nova Zelândia foi o $4^{\circ}$ (quarto) país do mundo a adotar o modelo tradicional de Ombudsmen em 1962. A Austrália passou a contemplá-lo no início da década de 1970, inclusive nos seus Estados-Membros ${ }^{22}$. Estas agências governamentais foram inseridas na Administração Pública e regulamentadas há mais de 40 (quarenta) anos nos dois países, e também passaram a atuar no tratamento do direito à informação pública ${ }^{23}$.

Sem embargo, suas recomendações e relatórios produzem considerável influência para corrigir eventuais falhas administrativas e procedimentos equivocados dos agentes públicos. Ombudsmen nesses países são regidos normalmente por um conjunto de leis denominado "whistleblowers legislation" e seus departamentos atuam através de "guidelines" consistentes que orientam a atividade da Ouvidoria. Em ambos os sistemas, já existem diversos precedentes judiciais que envolveram a atuação desses órgãos, e que dão o contorno necessário para o exercício de suas atribuições, com base jurídica e sem excessos.

De modo geral, essas Ouvidorias servem como porta de entrada para que solicitações, críticas e reclamações sejam encaminhados aos setores governamentais correspondentes para ciência e adoção de providências, todavia as denúncias de má administração e corrupção são apuradas pela própria Ouvidoria, que goza de prerrogativas substanciais no que diz respeito à autonomia e independência investigativa.

Deste modo, Ombudsmen são dotados de poderes similares aos das nossas Comissões Parlamentares de Inquérito (CPIs), podendo, inclusive, conduzir coercitivamente testemunhas, realizar buscas e apreensões, acessar documentos governamentais sigilosos, colher depoimentos sob pena de falso testemunho, sobrepor-se a decisões de órgãos públicos sobre pedidos de acesso à informação que foram negados, dentre outras atribuições.

As Ouvidorias neozelandesas e australianas vão mais além, sendo comum qualificá-las também como órgãos mediadores ou como mecanismos alternativos de solução de litígio. Os que chefiam o setor gozam de prestígio tanto na sociedade quanto no setor público, sendo o Ouvidor usualmente um servidor publico sênior, imparcial, com credibilidade e dedicação exclusiva ao cargo,

21 A Nova Zelândia obteve o $2^{\circ}$ lugar enquanto a Austrália ocupa o $13^{\circ}$ lugar do ranking. Ver Corruption perceptions Index 2016, Transparency International.

22 www.anzoa.com.au/assets/ombudsman-services-in-australia-and-new-zealand.pdf

23 Sobre o direito fundamental de acesso à informação, na Nova Zelândia vigora a legislação desde 1982 (Official Information Act), enquanto na Austrália ela é vigente desde 1991 (Freedom of Information Act).

170 | Revista Científica da Associação Brasileira de Ouvidores/Ombudsman - Ano 1 - n 1 - 2017/2018 
pelo que suas orientações e recomendações normalmente são atendidas e aceitas pelos órgãos administrativos, o que impede, por exemplo, que demandas desnecessárias envolvendo o Estado no polo passivo se avolumem no Poder Judiciário ${ }^{24}$.

Em que pesem as realidades distintas, pode se dizer que o modelo de Ombudsmen apresenta certas similaridades com as Ouvidorias Públicas Brasileiras.

Não resta a menor dúvida de que ambas são estruturas estatais concebidas para conferir transparência e abertura para o cidadão melhor fiscalizar os atos praticados pelo governo. De igual modo, quando foram introduzidas nos países acima destacados, as Ouvidorias representaram uma mudança de cultura no setor público, e muitas dificuldades foram encontradas para a sua inserção na atividade administrativa, o que parece indicar uma problemática comum desses modelos, seja atualmente no Brasil, seja no passado na Austrália ou Nova Zelândia.

Em adição, ambos convergem na sua filosofia de atuação, pois funcionam como meio de comunicação qualificado entre os cidadãos e o governo, atendendo ao público presencialmente ou através dos meios eletrônicos, recebendo as suas manifestações, sem cobrar nenhuma taxa para este tipo de serviço, elaborando relatórios anuais.

Vale ressaltar ainda outro ponto tangente entre esses departamentos que é a gestão da informação, já que tanto no Brasil quanto nesses países os modelos instituídos têm exercido a função de supervisão e/ou instância revisora dos pedidos de acesso à informação negados pelas unidades administrativas ou serviços de informação, pelo que tem se consolidado o entendimento geral de que elas são as estruturas estatais aptas a trabalhar com o direito fundamental de acesso à informação pública.

\section{Ombudsmen Parlamentares na Austrália e na Nova Zelândia e as Ouvidorias Le- gislativas: algumas semelhanças e diferenças}

Sem embargo dos pontos tangentes e divergentes dessas Ouvidorias nesses países com as Ouvidorias Públicas no Brasil, é de ser ressaltada a maior proximidade ainda do modelo de Ombudsmen com as nossas Ouvidorias Legislativas, apesar das suas diferenças.

Embora a nomenclatura "Ombudsmen" ou "Ombudsman" no Brasil esteja difundida para outros setores, inclusive para o setor privado, o que muitas vezes causa confusão, o que se entende por Ombudsmen no setor público, no exterior, são as estruturas da Administração Pública tradicionalmente vinculadas ao Poder Legislativo e não ao Poder Executivo ou ao Poder Judiciário, o que os aproxima muito mais das nossas Ouvidorias Legislativas do que das demais Ouvidorias Públicas.

E isto se explica, pois, historicamente, uma das primeiras funções atribuídas ao Poder Legis-

24 Para exemplificar, em 2006, um total de 849 casos foram submetidos à Corte da Nova Zelândia envolvendo litígios civis, penais e administrativos, todavia, nesse mesmo ano, 8.824 manifestações foram realizadas perante o Ombudsman que envolvem exclusivamente causas com potencial litígio contra o Estado, restando evidente que uma parcela mínima foi submetida ao Poder Judiciário, sendo a grande maioria resolvida sem a necessidade de ingressar em juízo, devido a atuação do Ombudsman. Ver Ministry of Justice Annual Report 2005/2006 (Nova Zelândia, Wellington, 2006), p. 130. 
lativo enquanto órgão de atuação estatal, foi a de fiscalizar a atuação do Poder Executivo, remontando à Magna Carta de 1215 que limitou os poderes de monarcas na Inglaterra. Por este motivo, é justificável que o Ombudsman instituído em 1809 na Suécia, como o pioneiro de todos e como uma agência independente, tinha sua estrutura vinculada ao Parlamento, pois somente assim ele teria legitimidade para investigar o Poder Executivo ${ }^{25 .}$

Naturalmente, portanto, o Poder Legislativo é o titular tradicional do poder-dever típico de fiscalizar toda a Administração Pública na consagrada teoria da separação dos três poderes, prerrogativa esta que não tem a mesma extensão para o Poder Executivo e para o Poder Judiciário, que a exercem de forma atípica. É verdade que o controle interno pode ser exercido por todos os Poderes, mas o controle externo é titularizado somente pelo Poder Legislativo.

Assim sendo, Ombudsmen nos países acima seguem essa tradição e por isso estão chancelados para atuar pelo Parlamento, logo são chamados de Ombudsmen Parlamentares (Parliamentary Ombudsmen), pois prestam contas das suas ações ao Legislativo e não ao Executivo, inexistindo qualquer vínculo de subordinação com o governo vigente ou partidos políticos. Tanto as nomeações dos seus titulares como a divulgação dos seus relatórios ocorrem dentro do Parlamento. Logo, Ombudsmen têm sua natureza jurídica originariamente vinculada ao Legislativo, assim como as nossas Ouvidorias Legislativas.

Seguindo esta linha de raciocínio, as Ouvidorias Legislativas são as que possuem vocação natural e legitimidade para ter uma posição de relevo no recebimento de manifestações do público que versem sobre o controle de toda a Administração Pública, e não somente no exercício do controle interno do órgão a que pertence.

Em tese, são as Ouvidorias Legislativas as que apresentam um espectro mais amplo de possibilidades no recebimento de denúncias que são formuladas pelo cidadão, pois as manifestações encaminhadas podem envolver quaisquer órgãos e agentes da Administração Pública sujeitos à atividade de fiscalização político-administrativa, financeira, contábil, orçamentária e patrimonial, que é ínsita ao Poder Legislativo.

Como fundamento, basta cotejar o que prescreve o art. 70 e seguintes da Constituição Federal de 1988 para entender a dimensão de possibilidades em que uma Ouvidoria Legislativa pode atuar e que, através do princípio da simetria, também se estende aos Poderes Legislativos dos Estados e Municípios:

Art. 70. A fiscalização contábil, financeira, orçamentária, operacional e patrimonial da União e das entidades da administração direta e indireta, quanto à legalidade, legitimidade, economicidade, aplicação das subvenções e renúncia de receitas, será exercida pelo Congresso Nacional, mediante controle externo, e pelo sistema de controle interno de cada Poder.

Parágrafo único. Prestará contas qualquer pessoa física ou jurídica, pública ou privada, que utilize, arrecade, guarde, gerencie ou administre dinheiros, bens e valores públicos ou pelos quais a União responda, ou que, em nome desta, assuma obrigações de natureza pecuniária.

Art. 71. O controle externo, a cargo do Congresso Nacional, será exercido com o auxílio do Tribunal de Contas da União, ao qual compete:

25 www.anzoa.com.au/assets/200_years_of-ombudsman.pdf 
I - apreciar as contas prestadas anualmente pelo Presidente da República, mediante parecer prévio que deverá ser elaborado em sessenta dias a contar de seu recebimento; II - julgar as contas dos administradores e demais responsáveis por dinheiros, bens e valores públicos da administração direta e indireta, incluídas as fundações e sociedades instituídas e mantidas pelo Poder Público federal, e as contas daqueles que derem causa a perda, extravio ou outra irregularidade de que resulte prejuízo ao erário público;

III - apreciar, para fins de registro, a legalidade dos atos de admissão de pessoal, a qualquer título, na administração direta e indireta, incluídas as fundações instituídas e mantidas pelo Poder Público, excetuadas as nomeações para cargo de provimento em comissão, bem como a das concessões de aposentadorias, reformas e pensões, ressalvadas as melhorias posteriores que não alterem o fundamento legal do ato concessório;

IV - realizar, por iniciativa própria, da Câmara dos Deputados, do Senado Federal, de Comissão técnica ou de inquérito, inspeções e auditorias de natureza contábil, financeira, orçamentária, operacional e patrimonial, nas unidades administrativas dos Poderes Legislativo, Executivo e Judiciário, e demais entidades referidas no inciso II;

$V$ - fiscalizar as contas nacionais das empresas supranacionais de cujo capital social a União participe, de forma direta ou indireta, nos termos do tratado constitutivo;

VI - fiscalizar a aplicação de quaisquer recursos repassados pela União mediante convênio, acordo, ajuste ou outros instrumentos congêneres, a Estado, ao Distrito Federal ou a Município;

VII - prestar as informações solicitadas pelo Congresso Nacional, por qualquer de suas Casas, ou por qualquer das respectivas Comissões, sobre a fiscalização contábil, financeira, orçamentária, operacional e patrimonial e sobre resultados de auditorias e inspeções realizadas;

VIII - aplicar aos responsáveis, em caso de ilegalidade de despesa ou irregularidade de contas, as sanções previstas em lei, que estabelecerá, entre outras cominações, multa proporcional ao dano causado ao erário;

IX - assinar prazo para que o órgão ou entidade adote as providências necessárias ao exato cumprimento da lei, se verificada ilegalidade;

X - sustar, se não atendido, a execução do ato impugnado, comunicando a decisão à Câmara dos Deputados e ao Senado Federal;

XI - representar ao Poder competente sobre irregularidades ou abusos apurados.

Bem distante desta realidade, todavia, as Ouvidorias Legislativas brasileiras estão "na sua infância" ou na sua "fase embrionária" se comparadas aos modelos similares de Ouvidorias Legislativas existentes nos países mais desenvolvidos, a exemplo da Nova Zelândia e Austrália. As Ouvidorias Legislativas no Brasil têm atuado somente no âmbito do órgão a que pertencem.

As diferenças são marcantes nos critérios de independência, jurisdição, poderes, procedimento e prestação de contas.

Ao contrário das nossas Ouvidorias Legislativas, a estrutura equivalente nesses países (Ombudsmen) goza de considerável autonomia e independência para realizar as suas funções, com prestígio na sociedade. Sua jurisdição se estende a atos governamentais de outros Poderes desde que se enquadrem no conceito de má administração ou corrupção, e não somente aos atos praticados no âmbito do Parlamento.

Ombudsmen podem iniciar uma ação investigativa por conta própria e se espera a contribuição dos setores e agentes públicos envolvidos. Embora suas decisões ou conclusões não sejam vinculantes, suas recomendações são normalmente atendidas, causam constrangimento se não aceitas e raramente são revertidas pelo Judiciário. 
No Brasil, muitos cidadãos não sabem sequer que as Ouvidorias Legislativas existem na estrutura correspondente do seu Estado ou do seu Município, nem para qual finalidade elas podem ser acionadas, mesmo diante da norma constitucional acima que confere vastas ferramentas para o cidadão provocar a atividade fiscalizatória do Poder Legislativo, o que poderia ser feito através das suas Ouvidorias.

A verdade é que para alguns gestores públicos parece faltar interesse na sua instituição e divulgação, e para o cidadão não há confiança de que estruturas internas, dependentes, possam ser úteis ou obtenham algum resultado prático, isto somado ao nível de desgaste que assola o Parlamento brasileiro e a tudo que está relacionado a ele.

Para um estudioso em Ouvidorias ou Ombudsmen no setor público internacional como mecanismo consagrado de boas práticas administrativas, soa estranho em um país onde há denúncias sistemáticas de corrupção e má administração crônica não existir este canal qualificado, ou, quando existente, não ser a Ouvidoria Legislativa a via principal, a mais estruturada e eficaz para o recebimento e encaminhamento dessas manifestações.

\section{O Resgate da Função Fiscalizatória do Poder Legislativo através das Ouvidorias Legislativas}

O Poder Legislativo em nosso país tem sofrido uma desconstrução galopante, e isto acompanha tudo e todos que estejam vinculados ao Parlamento.

A sua relação com a sociedade apresenta-se como sofrível e muitos desejam que mudanças radicais sejam perpetradas nesta estrutura de Poder. As mudanças sonhadas não passam somente por uma alteração do perfil dos seus integrantes, mas também por uma maior profissionalização de suas atividades, dos serviços que são prestados e de uma completa mudança de mentalidade do modo como o legislativo deve funcionar.

Neste sentido, as Ouvidorias Legislativas ressurgem como uma ferramenta estratégica para que se construa um novo tipo de diálogo entre a sociedade e os parlamentares, já que o cenário atual é visto como desgastado e ultrapassado. Há inúmeros exemplos de como as Ouvidorias Legislativas poderiam inovar nesta relação, sendo necessária uma maior sensibilidade para o aperfeiçoamento da gestão administrativa nas Casas Legislativas e Cortes de Contas.

Por exemplo, existem determinadas situações que demandam capacitação apropriada de um Ouvidor-Geral como um verdadeiro mediador, como nos protestos que chegam às Casas Legislativas e aos Tribunais de Contas. O Ouvidor-Geral, desde que qualificado, é quem deveria receber os manifestantes e contribuir para que as reivindicações fossem "ouvidas" de forma imparcial e encaminhadas na formatação ideal para o destinatário mais adequado, com o compromisso de se obter uma resposta para os interessados.

Neste contexto, para o cidadão, a percepção de que o seu protesto ou sua manifestação foi entregue a um Ouvidor Legislativo que atuará de modo imparcial difere substancialmente, por exemplo, da entrega do manifesto a parlamentares vinculados ao governo vigente, que possuem outros interesses políticos a zelar e de quem já se conhece a linha de entendimento, ou até mesmo a um 
parlamentar de oposição, que é minoria e muito provavelmente não terá apoio suficiente para atender aos reclames formulados.

Por sua vez, é inegável que com o advento da Lei de Acesso à Informação - Lei 12.527/2011 (LAI) houve o impulso necessário para que as Ouvidorias Legislativas assumissem um papel destacado na gestão da informação dos órgãos públicos e como canal qualificado entre o cidadão e o Poder Público para o recebimento deste tipo de manifestação. Trata-se de um serviço público relevante que passa a ser prestado pelo Poder Legislativo ao cidadão, e as Ouvidorias Legislativas devem assumir este papel em definitivo.

Noutra via, as Ouvidorias Legislativas podem contribuir significativamente com os trabalhos das Comissões Parlamentares de Inquérito (CPIs), sendo o órgão que receberá as denúncias sobre o objeto investigado, incluindo-se, se for o caso, as anônimas, com a garantia de sigilo de identidade, centralizando-se em um só departamento a gestão das informações recebidas, o que evitaria o vazamento e o desgaste causado pelas informações desencontradas fornecidas pelos membros da $\mathrm{CPI}$, tantas vezes observadas na mídia, além de ajudar na produção do relatório final.

Ainda, as Ouvidorias Legislativas podem ter papel fundamental na agilização de projetos de lei que estão paralisados nas Comissões ou de processos de prestação de contas que não foram julgados, bem como no controle da reposição ao erário de ordenadores de despesas que foram condenados e na tramitação das proposições legislativas, realizando gestões junto aos parlamentares e conselheiros para que os prazos sejam cumpridos e que as atividades legislativas sejam mais céleres, mediante participação dos cidadãos.

Por fim, há muito espaço para a expansão das Ouvidorias Legislativas. Fala-se na instalação de Ouvidorias Itinerantes, na utilização de redes sociais e aplicativos para o recebimento de manifestações e monitoramento dos serviços públicos. O setor pode funcionar como um verdadeiro "termômetro" de toda a Administração Pública, já que o Legislativo é que detém a prerrogativa de maior supervisor dos atos governamentais, seja do ponto de vista econômico-contábil (Tribunais de Contas), seja pelo viés político-administrativo (Assembleias Legislativas, Câmaras Municipais), sugerindo, por exemplo, a realização de auditorias, audiências públicas e estudos para proposições legislativas sobre tópicos frequentemente reclamados pela sociedade.

\section{Considerações Finais}

Como foi dito alhures, as Ouvidorias Legislativas ainda estão em sua "fase embrionária". Atuam de forma tímida, interinamente.

Elas diferem entre si em muitos aspectos. Não há uniformidade ou simetria de tratamento ou interligação entre as Ouvidorias do Poder Legislativo da União e das demais Ouvidorias Legislativas. As Ouvidorias Legislativas ainda não possuem uma organização em nível nacional, pelo que elas não se comunicam nem compartilham os seus principais problemas. Não existe uma rede de Ouvidorias Legislativas, nem tampouco um sistema informatizado que possa mapear como anda a prestação de serviços legislativos no país. Elas não dialogam entre si, nem muitas vezes com as demais Ouvidorias Públicas. 
Um ponto importante para que as Ouvidorias Legislativas estejam preparadas para assumir funções relevantes é a qualificação dos agentes públicos que as integram. É fundamental que todos que estejam lotados no departamento, inclusive o Ouvidor-Geral, seja ele parlamentar ou não, tenham como pré-requisito uma preparação específica para as atividades próprias das Ouvidorias Parlamentares, inclusive a realização de cursos e certificação que são oferecidos por instituições reconhecidas.

Em contrapartida, há necessidade de que as Ouvidorias Legislativas recebam maior apoio das Casas Legislativas e Cortes de Contas a que estão vinculadas e das organizações que se preocupam com o desenvolvimento das Ouvidorias Públicas no Brasil, uma vez que não adianta ter instituições fortes no Poder Executivo e no Poder Judiciário sem que o sistema esteja coeso e sincronizado, com Ouvidorias Legislativas fortalecidas.

Há necessidade de que os agentes políticos e gestores dos órgãos integrantes do Poder Legislativo sejam mais bem esclarecidos da importância das Ouvidorias Legislativas através de simpósios, seminários, visitas, para que possam compreender este modelo novo de participação da sociedade no controle da atividade governamental, pois somente assim mudanças concretas serão realizadas.

Em suma, há grande expectativa de que a aprovação da Lei 13.460, de 26 de junho de 2017 , que dispõe sobre a participação, proteção e defesa dos direitos dos usuários dos serviços públicos da Administração Pública, represente um marco significativo para consolidar a atuação das Ouvidorias Públicas, inclusive as Ouvidorias Legislativas, para que elas sigam os exemplos de estruturas equivalentes mais desenvolvidas no exterior (Ombudsmen) e que possam contribuir para a formação de um novo Poder Legislativo tão aguardado em nosso país.

\section{REFERÊNCIAS}

CANOTILHO, J. J. Gomes; MENDES, Gilmar F.; SCARLET, Ingo W.; STRECK, Lenio L. (Coord.). Comentário à Constituição do Brasil. São Paulo: Saraiva/Almedina, 2013.

McGEE, David. Parliamentary Practice in New Zealand, 3. ed. 2005.

MORENO, Douglas. Good Governance Practices. LLM Research Paper. Faculty of Law, Victoria University of Wellington, 2008.

NEAVE, Colin. Exploring the Role of the Commonwealth Ombudsman in Relation to Parliament. Disponível em: http://www.aph.gov.au Melbourne. Acesso em: 2015.

PHILPOT, Megan. Ombudsman SA Annual Report 2013/2014. Adelaide, South Australia, 2014.

SANTOS, Fabiano. O Poder Legislativo nos Estados: Diversidade e Convergência. Rio de Janeiro: Editora FGV, 2001. 